\title{
REVISÃO
}

\section{Antioxidantes como nutracêuticos para mitigar estresse oxidativo em abelhas: revisão sistemática}

\author{
Jéssica Scheid da Silva ${ }^{1}$ (D), Marcello Ávila Mascarenhas ${ }^{1 *}$ (iD
}

Resumo - A necessidade de produzir alimentos em larga escala proporcionou uma expansão no uso de agrotóxicos nas últimas décadas. Por outro lado, um importante processo dessa dinâmica, a polinização, realizada por abelhas, é prejudicada pelo uso desses produtos considerados estressores do metabolismo destes artrópodes. Sendo assim, o objetivo desta revisão sistemática foi verificar se usar antioxidantes na suplementação da alimentação das abelhas pode mitigar efeitos do estresse oxidativo causado por agrotóxicos. A metodologia utilizada foi uma adaptação do método PRISMA para selecionar artigos relacionados ao tema, publicados nos últimos 20 anos nas áreas de Ciências da Saúde e Ciências Agrárias. Foram localizados 196 artigos, destes, 26 atenderam os critérios de elegibilidade e foram incluídos na pesquisa. Assim, foi possível afirmar que agrotóxicos agravam estresse oxidativo, afetam a sobrevivência, a indução da expressão de genes reguladores da saúde e interferem na prevalência de patógenos nas abelhas. Nesse contexto se concluiu que é indicado suplementar a alimentação destes insetos com compostos protetores de oxidação, mas é preciso que se desenvolvam estudos para determinar o antioxidante adequado como nutracêutico, a fase do desenvolvimento em que é mais eficaz a suplementação da dieta e a dose ideal para garantir menor susceptibilidade das abelhas aos agrotóxicos.

Palavras-chave: Apis mellifera. Agroquímicos. Suplementação Nutricional. Oxirredução.

\section{Antioxidants as nutraceuticals to mitigate oxidative stress in bees: systematic review}

\begin{abstract}
Food production on large scale has led to an expansion in the use of pesticides. An important process in this dynamic is the pollination, carried out by bees, which is affected by the use that of these products considered stressors of the metabolism of these arthropods. Given these facts, the objective of this review was to verify whether the use of antioxidants in supplementing bee feeding can mitigate the oxidative stress caused by pesticides. The methodology used was an adaptation of the PRISMA method, selecting articles related to the theme, published in the last 20 years. Out of 196 articles found, 26 met the eligibility criteria and were included in the research. Thus, it was possible to state that pesticides aggravate oxidative stress, affect survival, induce the expression of regulating health genes, and may interfere with the prevalence of pathogens in bees. In this context, it was concluded that it is indicated to supplement the feeding of these insects with oxidation-protective compounds, but it is necessary to develop studies to determine the appropriate antioxidant as a nutraceutical, the stage of development in which it is most effective and the ideal dose to ensure less susceptibility of bees to pesticides.
\end{abstract}

Keywords: Apis mellifera. Agrochemicals. Nutritional Supplementation. Oxidation-Reduction.

1 Centro Universitário Metodista IPA - Porto Alegre, RS, Brasil. E-mail: jscheid.bio@gmail.com. *Autor de correspondência: mmasca2012@gmail.com 


\section{Introdução}

O crescimento da população, o processo de urbanização, a elevação da renda, o incentivo à produção e consumo de biocombustíveis, culminaram no aumento considerável da demanda por alimentos e produtos agrícolas, a partir do ano de 2000 (BRASIL, 2018). Nesse contexto, não se pode ignorar a utilidade dos agroquímicos. O uso em alta escala, dos mais variados tipos de agrotóxicos no agronegócio é muito prejudicial ao equilíbrio ecológico (DOS SANTOS; OTESBELGUE; BLOCHTEIN, 2018) apesar de ser um fator de impacto no combate aos insetos pragas, que são aqueles organismos que contrariam o interesse humano, a vida ou a produção de alimentos (MEIRELLES et al., 2020). Assim como outros defensivos agrícolas, os inseticidas sistêmicos, por exemplo, deixam doses residuais tóxicas translocadas no floema, xilema e nas células vegetais afetando as espécies nocivas e também animais polinizadores que se alimentam ou coletam recursos florais dessas plantas (AMARO; GODINHO, 2012). Muitos estudos experimentais indicam que os agrotóxicos comprometem o deslocamento, as habilidades de memória, a cognição, interferem na capacidade de forrageamento nas abelhas operárias e dificultam o desenvolvimento da colônia (VANDAME et al., 1995; THOMPSON, 2003; DESNEUX; DECOURTYE; DELPUECH, 2007; MOMMAERTS et al., 2009; HENRY et al., 2012; HERBERT et al., 2014; PISA et al., 2017). Outro fato a se considerar é que os agroquímicos agem sinergicamente, entre si, com patógenos e estressores nutricionais, e desta forma seus efeitos negativos no comportamento, fisiologia e imunidade das abelhas podem ser ainda piores (ALAUX et al., 2010; GOULSON et al., 2015; PISA et al., 2017).

Os efeitos letais e subletais desses agentes químicos podem comprometer a sobrevivência de espécies animais, que não são seus alvos e, que beneficiam a biodiversidade e produtividade agrícola (DOS SANTOS; OTESBELGUE; BLOCHTEIN, 2018). Esses indivíduos são capazes de realizar a dispersão do pólen de forma aleatória entre as flores, promovendo uma etapa fundamental do processo reprodutivo das plantas e que se mostra um importante mecanismo ecológico perante os serviços ambientais que presta (BARBOSA et al., 2017). Avaliações baseadas nos bancos de dados da Food and Agricultural Organization (FAO), confirmam que $33 \%$ da alimentação humana depende em algum grau de cultivos polinizados pelas abelhas (KLEIN et al., 2006; FAO, 2018). Esses animais da ordem Hymenoptera pertencentes à superfamília Apidae, coletam néctar e pólen, enquanto contribuem com a reprodução das plantas através da polinização. As substâncias coletadas (néctar e pólen), ricas em compostos antioxidantes, são usadas para produzir o mel, fluído que subsidiará sua alimentação em época de escassez (PIRES et al., 2016).

Segundo Helmer et al. (2014), os efeitos dos herbicidas nas abelhas demonstram que o consumo crônico, em função da coleta de recursos contaminados, pode afetar a absorção de antioxidantes do tipo $\beta$ caroteno, reduzindo a capacidade de proteção celular contra os defensivos agrícolas. Esse efeito pode comprometer o desenvolvimento embrionário e larval, diferenciação celular, visão, reprodução e capacidade de resposta do sistema imunológico, embora não sendo fatal. Desta forma, fica evidente que a quantidade de 
defesas antioxidantes fica desequilibrada em relação à produção de radicais livres provocando o chamado estresse oxidativo (FERREIRA; ABREU, 2007).

Nestas situações, as espécies reativas de oxigênio em excesso oxidam, danificam lipídios celulares, proteínas e DNA, levando a sua modificação, frequentemente a sua inutilização ou inibindo a sua função normal (VALKO et al., 2007). Para evitar tais consequências, é importante garantir o controle da produção de radicais livres bem como assegurar níveis adequados de antioxidantes. Essas substâncias presentes na dieta, assumem grande importância como possíveis agentes protetores, reduzindo os danos oxidativos (FERREIRA; ABREU, 2007). Alguns produtos naturais com atividade protetora podem ser úteis no auxílio ao sistema protetor endógeno, podendo ser utilizados como nutracêuticos (ŠKERGET et al., 2005).

Há muitas evidências de que o déficit de substâncias que impedem a oxidação tem impacto significativo na vulnerabilidade das abelhas à ação dos agrotóxicos (CLAUDIANOS et al., 2006; MAO; SCHULER; BERENBAUM, 2013; ZHANG et al., 2015; PINHO; CALDAS; ZALUSKI, 2018; GAUTHIER et al., 2018). Sabendo que a nutrição natural de abelhas contém elementos capazes de proteger contra o desequilíbrio do sistema redução-oxidação (REDOX), o incremento da alimentação desses importantes polinizadores com compostos benéficos para a sua saúde, surge como potencial forma de manejo sustentável de insetos da ordem Hymenoptera, espécie Apis mellifera (BATISTA et al., 2018). Diante disto, este estudo teve como objetivo verificar se o uso de antioxidantes na suplementação da alimentação de abelhas pode mitigar efeitos do estresse oxidativo causado por agrotóxicos, através de uma revisão sistemática da literatura. Revisão sistemática é um método de síntese de evidências que avalia criticamente e interpreta todas as pesquisas relevantes disponíveis no meio científico sobre uma área de interesse. São estudos produzidos por uma metodologia confiável, rigorosa e auditável garantindo maior credibilidade ao estudo (BRASIL, 2012).

\section{Metodologia}

Buscou-se o espectro mais amplo possível das evidências, localizadas nas bases de dados bibliográficos, sobre o tema analisado e que respondiam à questão levantada. Foram utilizados artigos originais de estudos experimentais e revisões bibliográficas apresentados nas línguas inglesa, espanhola e/ou portuguesa, publicados entre os anos de 2000 e 2020, uma vez que este período representa a maior concentração de publicações referentes ao tema.

A busca utilizou os descritores em inglês: Apis mellifera, diet, antioxidants e pesticide, com o auxílio do operador booleano and. Esta estratégia se mostrou mais adequada porque a maioria dos estudos relacionados ao tema está redigido em língua inglesa, o que indica que ainda há muito para ser explorado em pesquisas nacionais sobre este assunto. As bases de dados utilizadas foram: Science Direct, CAPES (Portal de Periódicos da Coordenação de Aperfeiçoamento de Pessoal de Nível Superior), PubMed (US National Library of Medicine National Institutes of Health), SciElo (Scientific Eletronic Library Online), LILACS (Literatura Latino-Americana e do Caribe em Ciências da Saúde) e DOAJ (Directory of Open Acess Journals). Para 
elaboração do relato foi utilizada uma adaptação da diretriz do método PRISMA (Principais Itens para Relatar Revisões Sistemáticas e Meta-análises). A recomendação do PRISMA consiste em um checklist com 27 itens e um fluxograma de seleção de artigos (Figura 1) com quatro etapas aplicado aos achados.

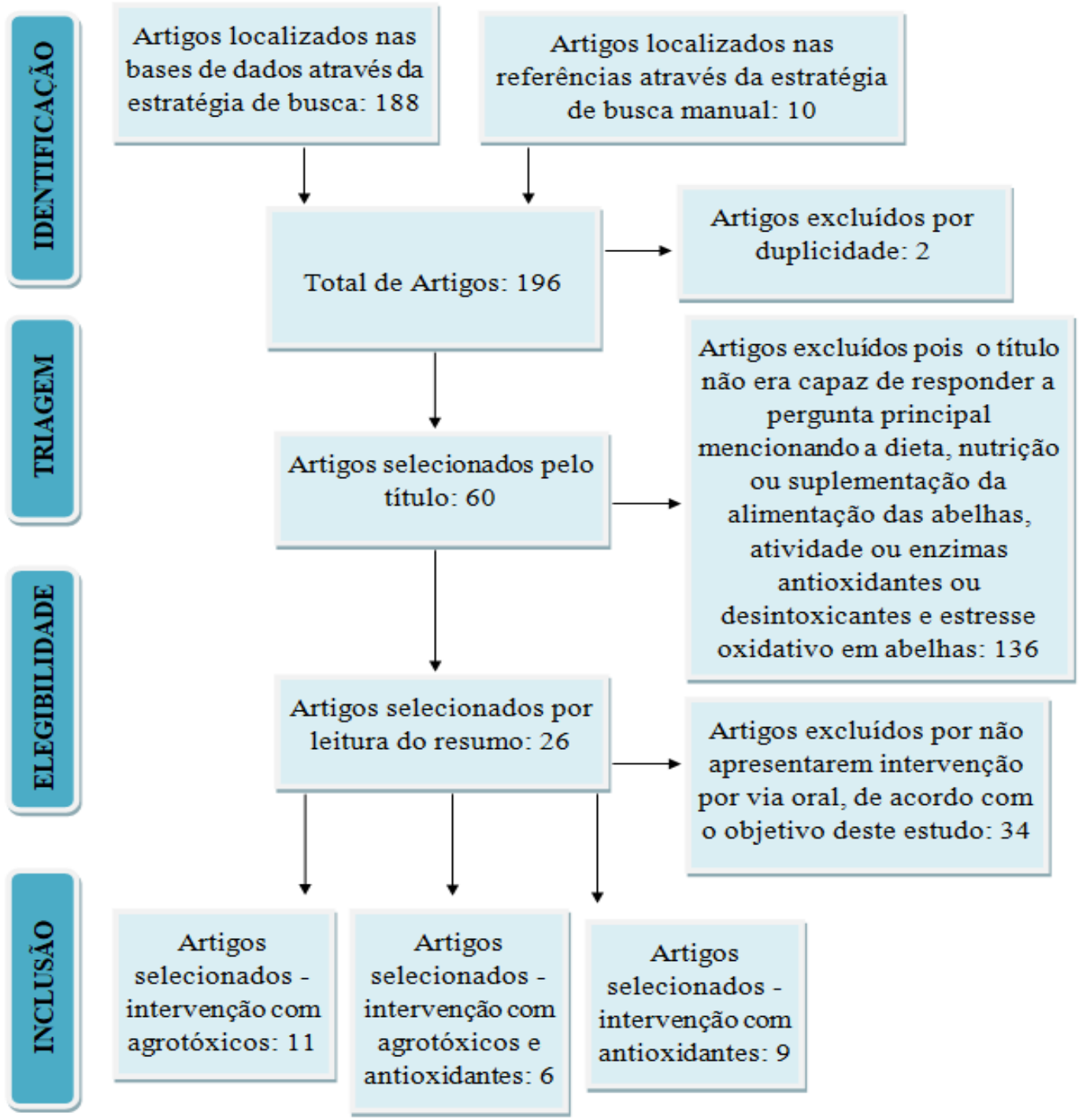

Figura 1. Fluxograma de seleção de artigos.

O fluxograma apresenta as quatro etapas de seleção dos artigos. A primeira etapa é a busca nas bases de dados e busca manual em outras fontes onde ocorre a identificação dos artigos. Na segunda etapa se realiza a triagem, excluindo títulos repetidos localizados nas buscas. O próximo passo é estabelecer critérios de elegibilidade que neste estudo os autores optaram por definir a intervenção por via oral como fator de inclusão ou exclusão uma vez que se trata de uma abordagem referente a alimentação das abelhas. Os artigos que atenderam esse requisito foram incluídos e segmentados em grupos para facilitar a coleta de dados e comparar os resultados das pesquisas incluídas. 
Ao realizar a busca, 118 artigos e capítulos de livros foram localizados no banco de dados Science Direct, 58 no Portal de Periódicos da CAPES, sete no PubMed e não foram encontrados resultados nas bibliotecas SciElo, LILACS e DOAJ. Nestes usou-se a estratégia de combinação dos descritores Apis mellifera, diet e antioxidants com o operador booleano and e foram localizados cinco artigos na DOAJ. Ainda por busca manual nas referências dos artigos selecionados, na área de Ciências Biológicas e Ciências Agrárias, foram localizados dez documentos com potencial de inclusão na discussão. Excluídos os títulos repetidos, totalizaram 196 artigos encontrados. Usando como critério de elegibilidade o título que fosse capaz de responder à pergunta problema, mencionando a dieta, nutrição ou suplementação da alimentação das abelhas, atividade ou enzimas antioxidantes ou desintoxicantes e estresse oxidativo nos insetos, foram selecionados 60 artigos no total e através desse filtro abrangente garantiu-se a leitura dos resumos e avaliação de todas as possíveis evidências.

Após a leitura dos resumos, adotou-se como critério de inclusão a intervenção por via oral de acordo com o objetivo deste estudo, e assim foram selecionados e sumarizados 26 artigos divididos em três grupos: intervenção com agrotóxicos na dieta, intervenção com antioxidantes na dieta e intervenção de ambos na dieta. Esses artigos foram submetidos à análise crítica e apresentaram maior expressão para compor esta sistemática. Com isso foi possível selecionar, interpretar, sintetizar, discutir e incluir as evidências de maior importância sobre o tema, para assim relatar e apresentar a conclusão desta Revisão Sistemática.

\section{Desenvolvimento}

\section{Suplementação da alimentação de abelhas}

Como todos os animais, as abelhas devem consumir certos nutrientes essenciais em sua dieta (BATISTA et al., 2018). Em condições normais, o néctar fornece os carboidratos que são convertidos em mel que é estocado nos alvéolos e utilizado como fonte de energia para suas funções vitais, enquanto o pólen supre às exigências de aminoácidos, lipídeos, minerais e vitaminas essenciais para o desenvolvimento da sua estrutura anatômica e fisiológica. A água é responsável pelo transporte e dissolução de substâncias servindo de meio para várias reações químicas (SEREIA, 2009; BARROS et al., 2017).

Segundo Pires et al. (2016), recomenda-se a complementação da alimentação das abelhas sempre que necessário, em época de escassez de oferta de pólen e néctar, ou mesmo em períodos produtivos (da primavera ao outono). Em função da sazonalidade na oferta de pólen das espécies da flora local ou cultivos agrícolas próximos, mesmo com disponibilidade de alimento, espécies botânicas que estejam em floração podem não suprir as necessidades nutricionais para garantir proteção ao organismo das abelhas. A sobrevivência desses seres é comprometida devido à deficiência de nutrientes, o que interfere no desenvolvimento, manutenção e reprodução das colônias, diminuindo a produção de crias, consequentemente, de abelhas adultas, levando à redução da força de trabalho da colônia e diminuindo o tempo de vida das abelhas. A prática de usar substitutos do mel é bastante difundida entre os apicultores como forma de economia de custos e aumento na 
produtividade. Essa prática antiga foi adotada após estudos laboratoriais demonstrarem a aceitabilidade e equivalência nutricional dos compostos com sacarose e frutose, e o mel (BARKER; LEHNER, 1978). No entanto, essa avaliação foi realizada antes da introdução dos pesticidas, na ocasião a demanda por expressão de desintoxicantes e resposta imune era menor, diferente do que ocorre agora em função do aumento do uso de agrotóxicos. O amplo uso de substitutos do mel na alimentação artificial de colônias, incluindo xarope de milho com alto teor de frutose, pode comprometer a capacidade das abelhas de lidar com defensivos agrícolas, patógenos e contribuir para a perda de colônias (MAO; SCHULER; BERENBAUM, 2013).

Na composição dos grãos de pólen encontramos compostos fenólicos dentre os quais um que se destaca é o ácido p-cumárico, presente na antera do arranjo floral de algumas espécies de plantas, no mel e no própolis, que são produtos da colmeia, portanto faz parte da dieta natural das abelhas, e pode funcionar como um alimento nutracêutico capaz de regular o sistema imune e de desintoxicação das abelhas. Análises realizadas por Mao, Schuler e Berenbaum (2013) revelaram que esse ácido possui propriedades antioxidantes e regula especificamente as classes de genes de desintoxicação. O consumo natural destes compostos foi mensurado e alcançou a concentração de 5,88 $\pm 0,12 \mu \mathrm{g} \cdot \mathrm{g}^{-1}$ no mel e 31,92 $\pm 5,74 \mu \mathrm{g} \cdot \mathrm{g}^{-1}$ no pão de abelha, forma como o pólen é consumido. Para o experimento foram fornecidas doses de $82 \mu \mathrm{g} \cdot \mathrm{g}^{-1}$ pois esta quantidade não é tóxica para indivíduos adultos e diante do consumo natural mensurado previamente seria uma medida capaz de influenciar a expressão gênica.

\section{Antioxidantes}

Os antioxidantes são substâncias capazes de neutralizar um radical livre, fornecendo o elétron que eles precisam. São agentes responsáveis por reduzir as lesões causadas pela presença dos chamados radicais livres nas células, ou seja, eles retardam ou bloqueiam o processo de oxidação produzido pela presença desses radicais, protegendo as células (SIES, 1993). Alguns produtos naturais com atividade antioxidante podem ser úteis no auxílio do sistema protetor endógeno, podendo ser utilizados como nutracêuticos (ŠKERGET et al., 2005).

As defesas antioxidantes enzimáticas existem em grande número e encontram-se espalhadas por todo o organismo, tanto no meio intracelular como no meio extracelular. Exemplo destas defesas são as enzimas Superóxido Dismutase (SOD), Catalase (CAT), Glutationa Peroxidase (GPH-Px), Glutationa Redutase (GPHR), entre outras. Entre as defesas antioxidantes não enzimáticas, destacam-se compostos como a Glutationa (GSH), o $\alpha$-tocoferol (Vitamina E), o ácido ascórbico (Vitamina C), o Ácido Lipóico, os carotenóides, os flavonóides etc. (VALKO et al., 2007).

O estudo de Gauthier et al. (2018) aponta que inseticidas podem ter efeito pró-oxidante em abelhas expostas a esses agrotóxicos. Esta conclusão foi obtida pois ao mensurar os biomarcadores como: atividade da acetilcolinesterase (AChE), peroxidação lipídica (LPO), concentração de $\alpha$-tocoferol, além de várias formas de vitamina A (retinóides) e carotenóides se percebeu alterações que induzem tal desfecho. 
Baseado em todas essas evidências, a arte do tema foi desenvolvida trazendo os artigos que aprimoram e corroboram com esses achados. O primeiro grupo de artigos trouxe como característica a intervenção por via oral com agrotóxicos (Tabela 1).

Tabela 1. Estudos com intervenção de agrotóxicos na dieta.

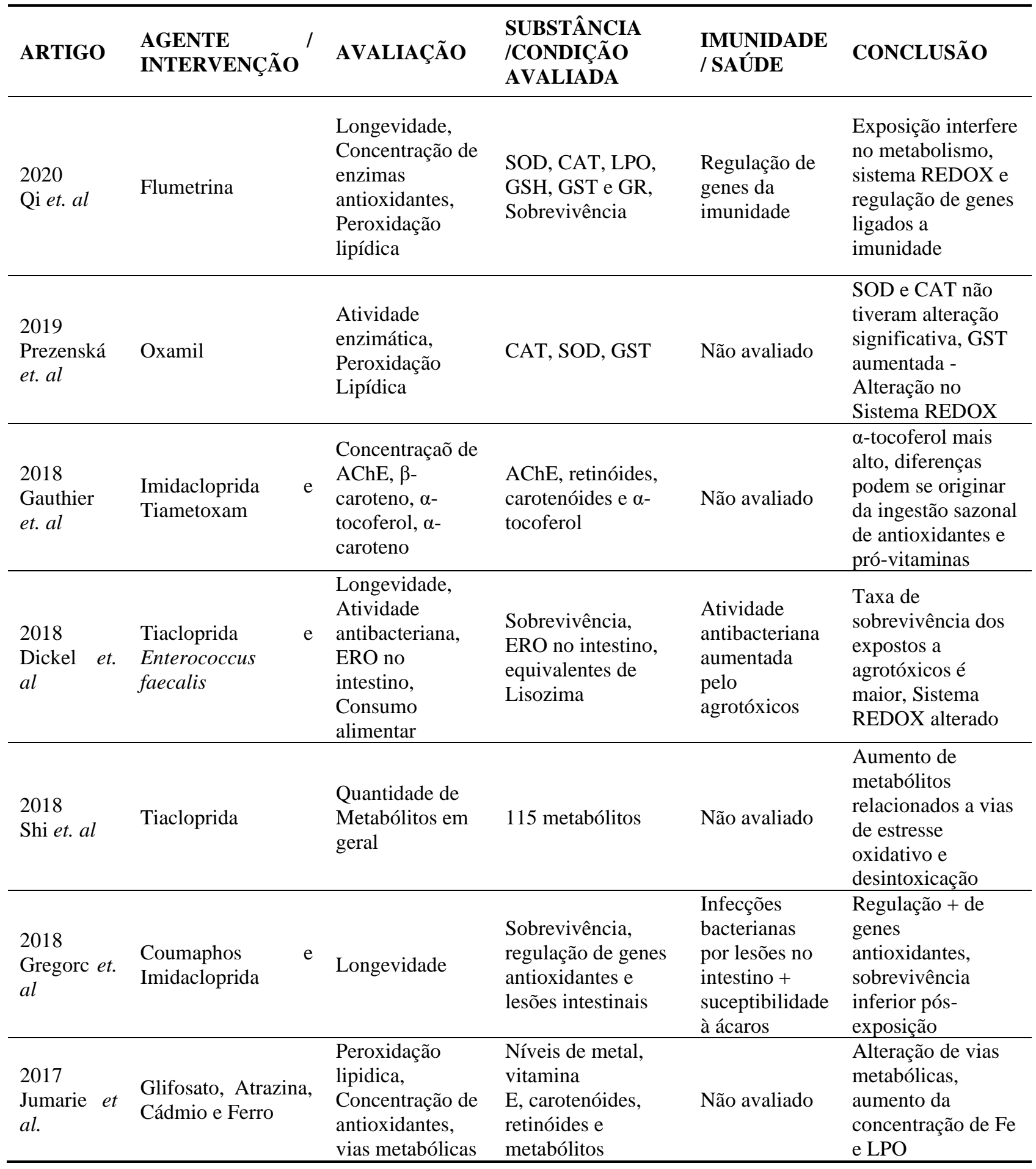




\begin{tabular}{|c|c|c|c|c|c|}
\hline $\begin{array}{l}2017 \\
\text { Boily et. al }\end{array}$ & $\begin{array}{l}\text { Fertilizantes de } \\
\text { cultivo de milho }\end{array}$ & $\begin{array}{l}\text { Metais e } \\
\text { Concentração de } \\
\text { Enzimas } \\
\text { antioxidantes }\end{array}$ & $\begin{array}{l}\text { LPO, Proteínas de } \\
\text { Metalotioneína } \\
\text { (MTLPs), } \\
\text { proteínas, retinóides } \\
\text { e antioxidantes } \\
\text { lipofílicos } \\
\text { (carotenóides e } \alpha- \\
\text { tocoferol) }\end{array}$ & Não avaliado & $\begin{array}{l}\text { Existe aumento de } \\
\text { danos oxidativos } \\
\text { que podem alterar } \\
\text { a regulação fina } \\
\text { dos retinóides. }\end{array}$ \\
\hline $\begin{array}{l}2016 \\
\text { Gong; } \\
\text { Diao }\end{array}$ & Xenobióticos & $\begin{array}{l}\text { Genes de } \\
\text { desentoxicação, } \\
\text { Citocromo P450 }\end{array}$ & P450, GST & Não avaliado & $\begin{array}{l}\text { Genes } \mathrm{P} 450 \text { e os da } \\
\text { imunidade podem } \\
\text { ser regulados pela } \\
\text { nutrição }\end{array}$ \\
\hline $\begin{array}{l}2016 \\
\text { Démares } \\
\text { et. al }\end{array}$ & Tiametoxam & $\begin{array}{l}\text { Longevidade, } \\
\text { consumo de } \\
\text { alimentos e } \\
\text { sensibilidade à } \\
\text { sacarose }\end{array}$ & $\begin{array}{l}\text { Sobrevivência, } \\
\text { consumo de } \\
\text { alimentos, reflexo } \\
\text { de extensão da } \\
\text { tromba }\end{array}$ & Não avaliado & $\begin{array}{l}\text { Na presença de um } \\
\text { pesticida e } \\
\text { alimentação } \\
\text { desequilibrada, a } \\
\text { saúde das abelhas } \\
\text { pode ser } \\
\text { severamente } \\
\text { prejudicada }\end{array}$ \\
\hline
\end{tabular}

\begin{tabular}{|c|c|c|c|c|c|c|}
\hline $\begin{array}{l}2014 \\
\text { Helmer et. } \\
\text { al }\end{array}$ & $\begin{array}{l}\text { Atrazina, } \\
\text { Metolachlor } \\
\text { Glifosato }\end{array}$ & $\mathrm{e}$ & $\begin{array}{l}\text { Peroxidação } \\
\text { lipidica, } \\
\text { Concentração de } \\
\text { antioxidantes }\end{array}$ & LPO e $\beta$-caroteno & Não avaliado & $\begin{array}{l}\text { Dieta com } \\
\text { antioxidantes } \\
\text { interfere na } \\
\text { resistência a } \\
\text { agrotóxicos }\end{array}$ \\
\hline
\end{tabular}

Enzimas SOD - Superóxido Dismutase , CAT - Catalase, GST - Glutationa-S-Transferase, GR - Glutationa Redutase, AchE - Acetilcolinesterase. Outras siglas: GSH - Glutationa, LPO - Peóxidação Lipídica, P450 - Citocromo P450, REDOX - Oxirredução, ERO - Espécies Reativas de Oxigênio, MTLPs - Proteínas de Metalotioneína.

Os artigos encontrados trazem evidências de que alimentação, estresse oxidativo em função da exposição a agrotóxicos e saúde das abelhas estão muito vinculados. Quando avaliadas as enzimas do metabolismo antioxidante endógeno, percebe-se que apesar de algumas concentrações ou atividades não terem alterações relevantes em determinadas situações, em outros experimentos podem se apresentar alteradas, indicando que ocorrem importantes mecanismos de compensação no organismo das abelhas.

Prezenská, Sobeková e Sabová (2019) encontraram resultados que evidenciam que mesmo uma pequena alteração na ativação de enzimas antioxidantes promove a ativação do sistema redução/oxidação (REDOX) e já é capaz de mitigar os efeitos adversos provocados pelo estresse oxidativo. Gauthier et al. (2018) sugeriram que as alterações nas concentrações de $\alpha$-caroteno, $\alpha$-criptoxantina e $\alpha$-tocoferol estão relacionados ao aumento dos metabólitos oxidados em função da exposição ao tiametoxam. Além disso, afirmam ainda que também a peroxidação lipídica verificada pode se originar na ingestão sazonal mais baixa de antioxidantes, visto que o estudo foi realizado em época onde ocorre uma mudança considerável nas plantações de flores, indicando que uma compensação do déficit no sistema endógeno que controla o estresse oxidativo poderia ocorrer pela ingestão de antioxidantes na dieta das abelhas. 
Outro fator analisado nos achados é a expressão de genes e enzimas desintoxicantes que a exposição a agroquímicos promove. O genoma das abelhas é caracterizado por uma escassez de genes associados à desintoxicação, mas existem genes específicos que tem sua expressão regulada por constituintes do mel e do pólen e resultam na tolerância das abelhas a alguns agrotóxicos (GONG; DIAO, 2016). Portanto supõe-se que em função de uma maior demanda no controle dos impactos causados pela exposição a agentes agroquímicos, uma boa alimentação pode auxiliar na proteção ao estresse. Helmer et al. (2014) indicam que, com o aumento da dose de agrotóxico utilizada na intervenção, os níveis de antioxidantes testados diminuem apesar de não terem vínculo evidente com a peroxidação lipidica verificada nos experimentos. Boily, Aras e Jumarie (2017) e Jumarie, Boily e Aras (2017) evidenciaram alterações nas vias metabólicas e risco de aumento a danos oxidativos nas abelhas expostas a combinações de agrotóxicos e metais.

Mais um achado importante foi descrito por Dickel et al. (2018) que expos abelhas a agrotóxicos e bactérias. Percebe-se uma relação supostamente positiva no combate aos microorganismos com a exposição concomitante das cepas bacterianas e o inseticida tiacloprida. Apesar da atividade antibacteriana geral ser aumentada, resultando em uma maior resposta imunológica observada nos indivíduos tratados em comparação aos indivíduos controle, o controle da dieta pode levar ao aumento dos níveis de antioxidantes, que contribuem para a sobrevivência dos insetos, aumentando a resistência ao estresse provocado pelos inseticidas.

Ainda referente a patógenos, Gregorc et al. (2018) verificaram através de análises imuno-histológicas que coumaphos e as misturas de imidacloprida induziram a regulação negativa de genes antioxidantes com dano perceptível ao tecido do intestino médio, o que deixa as abelhas mais vulneráveis a infecções oportunistas de bactérias enquanto o imidacloprida induziu regulações positivas de genes e apresentou menos apoptose nas células do intestino médio. A descoberta de Démares et al. (2016) valida a hipótese levantada quando revela que independente da dose de tiametoxam, a sobrevivência é maior com dietas balanceadas. O segundo grupo de evidências (Tabela 2) utilizou tratamentos com pesticidas e com antioxidantes para mensurar a interferência de cada agente.

Tabela 2. Estudos com intervenção de agrotóxicos e antioxidantes na dieta.

\begin{tabular}{|c|c|c|c|c|c|}
\hline ARTIGO & $\begin{array}{l}\text { AGENTE } \\
\text { INTERVENÇÃO }\end{array}$ & AVALIAÇÃO & $\begin{array}{l}\text { SUBSTÂNCIA } \\
\text { AVALIADA }\end{array}$ & $\begin{array}{l}\text { IMUNIDADE / } \\
\text { SAÚDE }\end{array}$ & CONCLUSÃO \\
\hline $\begin{array}{l}2020 \\
\text { Mitton et al. }\end{array}$ & $\begin{array}{l}\text { Ácido p-cumárico, } \\
\text { Indol-3-Acético e } \\
\text { Tau-Fluvalinato }\end{array}$ & $\begin{array}{l}\text { Sobrevivência e } \\
\text { Atividade } \\
\text { Desintoxicação }\end{array}$ & $\begin{array}{l}\text { Citocromo } \\
\text { P450, } \\
\text { Glutationa } \\
\text { Redutase, } \\
\text { Sobrevivência }\end{array}$ & Não avaliado & $\begin{array}{l}\text { A suplementação } \\
\text { alimentar aumentou } \\
\text { os mecanismos de } \\
\text { desintoxicação e } \\
\text { eliminação de ERO } \\
\text { das abelhas }\end{array}$ \\
\hline
\end{tabular}




\begin{tabular}{|c|c|c|c|c|c|}
\hline $\begin{array}{l}2019 \\
\text { Mogren et } \\
\text { al. }\end{array}$ & $\begin{array}{l}\text { Clotianidina e } \\
\text { Pólen }\end{array}$ & $\begin{array}{l}\text { Atividade de } \\
\text { SOD, } \\
\text { Longevidade }\end{array}$ & $\begin{array}{l}\text { Sobrevivência, } \\
\text { SOD }\end{array}$ & Não avaliado & $\begin{array}{l}\text { SOD ligeiramente } \\
\text { mais elevada, } \\
\text { indicando que } \\
\text { suplementação é } \\
\text { importante para } \\
\text { mitigar estresse } \\
\text { oxidativo e } \\
\text { sobrevivência }\end{array}$ \\
\hline $\begin{array}{l}2018 \\
\text { Wong et al. }\end{array}$ & $\begin{array}{l}\text { Imidacloprida, } \\
\text { Ácido p-cumarico e } \\
\text { Quercetina }\end{array}$ & Longevidade & Sobrevivência & Não avaliado & $\begin{array}{l}\text { Há limites para os } \\
\text { efeitos protetores da } \\
\text { dieta natural das } \\
\text { abelhas contra os } \\
\text { neonicotinóides }\end{array}$ \\
\hline $\begin{array}{l}2017 \\
\text { de Mattos et } \\
\text { al. }\end{array}$ & Paraquat e Pólen & $\begin{array}{l}\text { Expressão de } \\
\text { genes de } \\
\text { antioxidantes, } \\
\text { de } \\
\text { desintoxicação e } \\
\text { de longevidade }\end{array}$ & $\begin{array}{l}\text { Sobrevivência, } \\
\text { CYP6S3, } \\
\text { GSTS4, PRXS, } \\
\text { SOD2, VG, } \\
\text { Incidência de } \\
\text { Nosema }\end{array}$ & $\begin{array}{l}\text { Suceptibilidade } \\
\text { a Nosema e } \\
\text { patógenos virais }\end{array}$ & $\begin{array}{l}\text { Paraquat apresenta } \\
\text { influência negativa } \\
\text { na expressão de } \\
\text { genes de enzimas } \\
\text { antioxidantes e } \\
\text { infecção de } \\
\text { microorganismo } \\
\text { Oferta de pólen } \\
\text { pode mitigar tanto } \\
\text { efeitos da exposição } \\
\text { ao herbicida quanto } \\
\text { da infecção por } \\
\text { patógenos }\end{array}$ \\
\hline $\begin{array}{l}2017 \\
\text { Liao et al. }\end{array}$ & $\begin{array}{l}\text { Bifentrina, } \beta \text {-c } \\
\text { flutrina, Quercetina } \\
\text { e Ácido p-cumárico }\end{array}$ & $\begin{array}{l}\text { Longevidade, } \\
\text { tolerância a } \\
\text { agrotóxicos }\end{array}$ & Sobrevivência & Não avaliado & $\begin{array}{l}\text { Fitoquímicos } \\
\text { dietéticos } \\
\text { influenciam a } \\
\text { longevidade das } \\
\text { abelhas e o estresse } \\
\text { oxidativo }\end{array}$ \\
\hline $\begin{array}{l}2012 \\
\text { Johnson et } \\
\text { al. }\end{array}$ & $\begin{array}{l}\text { Tau-fluvalinato, } \\
\text { Imidaclopride, } \\
\text { Fungos, } \\
\text { Fenobarbital }\end{array}$ & $\begin{array}{l}\text { Expressão gene } \\
\text { citocromo P450, } \\
\text { Longevidade }\end{array}$ & $\begin{array}{l}\text { Citocromo } \\
\text { P450, } \\
\text { Sobrevivência }\end{array}$ & Não avaliado & $\begin{array}{l}\text { Regulação do gene } \\
\text { P450s está } \\
\text { sintonizada com os } \\
\text { produtos químicos } \\
\text { que ocorrem } \\
\text { naturalmente } \\
\text { (antioxidantes) }\end{array}$ \\
\hline
\end{tabular}

Notas: (Enzimas SOD - Superóxido Dismutase , SOD2 - Cu/Zn-Superóxido Dismutase, GSTS4 - Glutationa-S Transferase S4, PRXS - Peroxirredoxinas. Outras siglas: P450 - Citocromo P450, ERO - Espécies Reativas de Oxigênio, CYP653 - Gene da família do Citocromo P450, VG - Vitelogenina).

Neste segundo conjunto de evidências percebemos que, de fato, o contato com os agroquímicos promove interferências no equilíbrio do Sistema de Oxirredução do metabolismo das abelhas e que a suplementação alimentar tem capacidade de mitigar os efeitos prejudiciais provocados. Os experimentos de Mitton et al. (2020) comprovam que a sobrevivência das abelhas após a exposição está diretamente ligada ao tipo de nutrientes consumidos. Uma dieta rica em compostos fitoquímicos antioxidantes é capaz de reduzir a taxa de mortalidade em abelhas Apis mellifera. Por outro lado, apesar de também indicar que a sobrevivência das abelhas está ligada à alimentação, é possível indentificarmos em outros estudos que o índice é variável e 
dependente tanto da concentração de agrotóxicos a que os organismos foram expostos, quanto da quantidade de suplementação alimentar ofertada (MOGREN; DANKA; HEALY, 2019).

A avaliação de sobrevivência dos animais também se mostra um indicador importante na avaliação da resistência a agrotóxicos. Concentração Letal média do agente tóxico (LC50) é a concentração que promove a morte de $50 \%$ do total dos indivíduos em cada grupo teste. Através da utilização desta dose é possível contabilizar se uma determinada quantidade de antioxidante ou a combinação de antioxidantes é capaz de evitar a morte de metade do total dos organismos avaliados (WONG; LIAO; BERENBAUM, 2018). Além disso, alguns estudos avaliam a expressão de genes de enzimas antioxidantes, de desintoxicação e de longevidade após o consumo de compostos antioxidantes que mostram que a oferta de pólen pode mitigar tanto os efeitos da exposição aos herbicidas, quanto da infecção por patógenos que promoveriam a morte das abelhas (DE MATTOS; SOARES; TARPY, 2017).

Com uma metodologia diferenciada usando a análise de modelos de risco proporcional de Cox, os estudos de Liao, Wu e Berenbaum (2017) mostram que os animais vulneráveis aos agrotóxicos e alimentados com a dieta habitual têm menor resistência, enquanto a suplementação de caseína, quercetina e ácido pcumárico apresentam influência positiva na longevidade dos organismos teste. Estes compostos fitoquímicos se mostram potenciais candidatos a nutracêuticos para abelhas.

Enquanto substâncias naturais se mostram eficientes para diminuir impactos negativos do contato das abelhas com agroquímicos, alguns compostos sintéticos, conhecidos por induzir a expressão de genes envolvidos na desintoxicação de insetos, não apresentam a mesma capacidade para abelhas. Exemplo disso é o fenobarbital, droga administrada a abelhas, mas que não foi capaz de induzir aumento na enzima Citocromo P450. Existem também evidências de que o consumo de xarope de milho, com altos níveis de sacarose e frutose, pode aumentar a toxicidade de toxinas ligadas a patógenos que afetam a saúde das abelhas (JOHNSON et al., 2012), mostrando que a suplementação com nutrâceuticos antioxidantes tem maior eficácia na manutenção da saúde em geral desses Hymnopteros. Na Tabela 3 constam os artigos que avaliaram somente a interferêcia dos antioxidantes na dieta.

Os artigos que enfatizam a atuação dos antioxidantes frente à exposição aos agentes estressores do sistema imunológico, de oxirredução e genético das abelhas, avaliam sobretudo a sobrevivência, as concentrações e atividades enzimáticas, a indução da expressão de genes reguladores da saúde e a prevalência de patógenos nestes seres. Baseado em estudos com insetos, Kojić et al. (2019) levantaram a hipótese de que nanopartículas de Fulerenol, uma forma alotrópica de carbono, é capaz de atenuar o estresse oxidativo em abelhas por apresentar propriedades antioxidantes. Para comprovar a suspeita avaliaram a sobrevivência, concentração e atividade das enzimas envolvidas no metabolismo antioxidante e de desintoxicação de abelhas em experimentos que promoveram comprometimento do sistema de oxirredução e posteriormente incluiram na dieta dos grupos avaliados o Fulerenol. Com os resultados obtidos os autores indicam que o composto de carbono tem papel protetor e não apresenta potencial tóxico para as abelhas. 
Tabela 3. Estudos com intervenção de antioxidantes na dieta.

\begin{tabular}{|c|c|c|c|c|c|}
\hline ARTIGO & $\begin{array}{l}\text { AGENTE / } \\
\text { INTERVENÇÃO }\end{array}$ & AVALIAÇÃO & $\begin{array}{l}\text { SUBSTÂNCIA } \\
\text { AVALIADA }\end{array}$ & $\begin{array}{l}\text { IMUNIDADE/ } \\
\text { SAÚDE }\end{array}$ & CONCLUSÃO \\
\hline $\begin{array}{l}2019 \\
\text { Kojić et al. }\end{array}$ & $\begin{array}{l}\text { Nanopartículas de } \\
\text { Fulerenol }\end{array}$ & $\begin{array}{l}\text { Toxicidade de } \\
\text { Fulerenol e seu } \\
\text { potencial } \\
\text { antioxidante }\end{array}$ & $\begin{array}{l}\text { Sobrevivência, } \\
\text { Concentração e } \\
\text { Atividade } \\
\text { enzimática de } \\
\text { CAT, Cu/Zn- } \\
\text { SOD, Mn-SOD, } \\
\text { GSTS1 }\end{array}$ & Não avaliado & $\begin{array}{l}\text { Indica papel } \\
\text { protetor de } \\
\text { nanopartículas de } \\
\text { Fulerenol em } \\
\text { abelhas expostas }\end{array}$ \\
\hline $\begin{array}{l}2017 \\
\text { Simone- } \\
\text { Finstrom et } \\
\text { al. }\end{array}$ & Própolis & $\begin{array}{l}\text { Benefícios da } \\
\text { exposição ao } \\
\text { própolis }\end{array}$ & $\begin{array}{l}\text { Atividades } \\
\text { antibacterianas e } \\
\text { vias de } \\
\text { desintoxicação }\end{array}$ & Não avaliado & $\begin{array}{l}\text { Talvez a própolis } \\
\text { possa, pelo menos } \\
\text { em parte, ajudar a } \\
\text { mitigar os efeitos } \\
\text { de estressores e } \\
\text { patógenos e por via } \\
\text { oral impulsiona o } \\
\text { metabolismo de } \\
\text { desintoxicação }\end{array}$ \\
\hline $\begin{array}{l}2016 \\
\text { Jack et al. }\end{array}$ & Pólen & $\begin{array}{l}\text { Longevidade e } \\
\text { Sinais de } \\
\text { infecção }\end{array}$ & $\begin{array}{l}\text { Sobrevivência, } \\
\text { contaminação por } \\
\text { fungos, } \\
\text { concentração } \\
\text { proteína da } \\
\text { glândula } \\
\text { hipofaríngea e } \\
\text { atividade } \\
\text { enzimática }\end{array}$ & $\begin{array}{l}\text { Suscetibilidade } \\
\text { a Nosema } \\
\text { ceranae }\end{array}$ & $\begin{array}{l}\text { Maior índice de } \\
\text { contaminação e } \\
\text { maior } \\
\text { sobrevivência } \\
\text { quando alimentadas } \\
\text { com doses maiores } \\
\text { de Pólen }\end{array}$ \\
\hline $\begin{array}{l}2015 \\
\text { Zhang et } \\
\text { al. }\end{array}$ & Zinco & $\begin{array}{l}\text { Concentração e } \\
\text { Atividade de } \\
\text { enzimas } \\
\text { antioxidantes e } \\
\text { Longevidade }\end{array}$ & $\begin{array}{l}\text { Sobrevivência, } \\
\text { Atividade Cu/Zn- } \\
\text { SOD e } \\
\text { Concentração de } \\
\text { Zn na geléia real }\end{array}$ & Não avaliado & $\begin{array}{l}\text { Maior atividade } \\
\mathrm{Cu} / \mathrm{Zn} \text {-SOD e } \\
\text { sobrevivência dose } \\
\text { dependente }\end{array}$ \\
\hline $\begin{array}{l}2014 \\
\text { Farjan et } \\
\text { al. }\end{array}$ & $\begin{array}{l}\text { Ácido Ascórbico, } \\
\text { (Vitamina C) }\end{array}$ & $\begin{array}{l}\text { Estado } \\
\text { Antioxidante } \\
\text { total, } \\
\text { Concentração e } \\
\text { Atividade } \\
\text { enzimática }\end{array}$ & $\begin{array}{l}\text { Glutationa, SOD, } \\
\text { CAT, Peroxidase } \\
\text { e Glutationa S- } \\
\text { transferase }\end{array}$ & $\begin{array}{l}\text { Índice de } \\
\text { infestação de } \\
\text { Varroa } \\
\text { destructor }\end{array}$ & $\begin{array}{l}\text { V. destructor tem } \\
\text { influência negativa } \\
\text { no sistema } \\
\text { antioxidante, } \\
\text { suplementação da } \\
\text { dieta com Vitamina } \\
\text { C é recomendada }\end{array}$ \\
\hline $\begin{array}{l}2013 \\
\text { Mao et al. }\end{array}$ & $\begin{array}{l}\text { Ácido p-Cumárico, } \\
\text { Pinocembrina e } \\
\text { Éter 5-Metílico de } \\
\text { Pinobanksina }\end{array}$ & $\begin{array}{l}\text { Genes de } \\
\text { desintoxicação e } \\
\text { genes de } \\
\text { peptídeos } \\
\text { antimicrobianos }\end{array}$ & $\begin{array}{l}\text { Citocromo P450, } \\
\text { CYP6 e CYP9, } \\
\text { CYP6AS e } \\
\text { enzimas CYP9Q } \\
\text { e CYP9Q }\end{array}$ & Não avaliado & $\begin{array}{l}\text { Constituintes } \\
\text { previsíveis de mel } \\
\text { servem como } \\
\text { indutores } \\
\text { específicos de } \\
\text { enzimas de } \\
\text { desintoxicação }\end{array}$ \\
\hline
\end{tabular}




\begin{tabular}{|c|c|c|c|c|c|}
\hline $\begin{array}{l}2013 \\
\mathrm{Di} \\
\text { Pasquale et } \\
\text { al. }\end{array}$ & Pólen & $\begin{array}{l}\text { Longevidade, } \\
\text { Fisiologia } \\
\text { Nutricional, } \\
\text { Tolerância a } \\
\text { infecção, } \\
\text { Atividade } \\
\text { enzimática }\end{array}$ & $\begin{array}{l}\text { Desenvolvimento } \\
\text { da glândula } \\
\text { hipofaríngea e } \\
\text { nível de VG, } \\
\text { Sobrevivência, } \\
\text { Atividade da } \\
\text { Fosfatase } \\
\text { Alcalina, } \\
\text { Fenoloxidase e } \\
\text { Glutationa-S- } \\
\text { Transferase }\end{array}$ & $\begin{array}{l}\text { Suscetibilidade } \\
\text { a Nosema } \\
\text { ceranae }\end{array}$ & $\begin{array}{l}\text { Dependendo fase de } \\
\text { desenvolvimento a } \\
\text { qualidade e a } \\
\text { diversidade do } \\
\text { pólen afetam a } \\
\text { fisiologia, } \\
\text { tolerância a } \\
\text { patógenos e a } \\
\text { sobreviência das } \\
\text { abelhas. }\end{array}$ \\
\hline $\begin{array}{l}2012 \\
\text { Foley et al. }\end{array}$ & $\begin{array}{l}\text { Pólen de Dente de } \\
\text { Leão (Taraxacum } \\
\text { officinale) ou } \\
\text { Polifloral }\end{array}$ & $\begin{array}{l}\text { Longevidade e } \\
\text { sinais de } \\
\text { infecção }\end{array}$ & $\begin{array}{l}\text { Sobrevivência e } \\
\text { contaminação por } \\
\text { fungos }\end{array}$ & $\begin{array}{l}\text { Suscetibilidade } \\
\text { a Aspergillus } \\
\text { flavus, } \\
\text { Aspergillus } \\
\text { phoenicis e } \\
\text { Aspergillus } \\
\text { Fumigatus }\end{array}$ & $\begin{array}{l}\text { A limitação } \\
\text { nutricional } \\
\text { compromete a } \\
\text { capacidade de } \\
\text { sobrevivência } \\
\text { dependendo do } \\
\text { patógeno }\end{array}$ \\
\hline $\begin{array}{l}2011 \\
\text { Alaux et } \\
\text { al. }\end{array}$ & Pólen & $\begin{array}{l}\text { Genes ligados a } \\
\text { longevidade e a } \\
\text { produção de } \\
\text { peptídeos } \\
\text { antimicrobianos }\end{array}$ & $\begin{array}{l}\text { Sobrevivência, } \\
\text { Vias metabólicas }\end{array}$ & $\begin{array}{l}\text { Suscetibilidade } \\
\text { a Varroa }\end{array}$ & $\begin{array}{l}\text { Pólen estimula } \\
\text { expressão de genes } \\
\text { relacionados a } \\
\text { longevidade e } \\
\text { defesas } \\
\text { antioxidantes, } \\
\text { apesar de não } \\
\text { contribuir contra } \\
\text { patógenos } \\
\end{array}$ \\
\hline
\end{tabular}

Enzimas CAT - Catalase, SOD - Superóxido Dismutase , Cu/Zn-SOD - Cobre/Zinco-Superóxido Dismutase, Mn-SOD - Manganês - Superóxido Dismutase, GSTS1 - Glutationa-S-Transferase S1. Outras siglas: P450 - Citocromo P450, CYP6, CYP9, CYP6AS, CYP9Q e CYP9Q - Genes da família do Citocromo P450 e codificadores de enzimas, Zn Zinco.

A própolis é uma resina que como agente externo tem valor protetor antibacteriano conhecido, e por via oral impulsiona o metabolismo de desintoxicação como indicado na revisão de Simone-Finstrom et al. (2017). Um composto fundamental na alimentação das abelhas é o pólen. Ele está presente na sua dieta habitual e tem se apresentado como importante regulador de defesas. Todas as evidências revisadas que utilizaram pólen no tratamento dos grupos experimentais, avaliaram a sobrevivência e a susceptibilidade a patógenos, sendo que todos demonstraram forte vínculo entre a capacidade imunológica e o consumo de pólen (JACK et al., 2016; DI PASQUALE et al., 2013; FOLEY et al., 2012). Pode-se afirmar também que a quantidade diária de pólen consumido interfere na resposta imune, bem como determina a expressão de genes relacionados à longevidade e defesas antioxidantes (ALAUX et al., 2011). Sabendo que a alimentação é capaz de contribuir com o mecanismo de Oxirredução do metabolismo, o estudo das enzimas envolvidas nestes processos facilita a compreensão das interações dos nutrientes ingeridos e os processos bioquímicos envolvidos.

O zinco é um mineral indispensável para abelhas (ZHANG et al., 2015). Ele é um dos componentes da Cobre/Zinco - Superóxido Dismutase (Cu/Zn-SOD ou SOD1), a principal enzima antioxidante que atua em moléculas de espécies reativas de oxigênio (EROs) e que protege a integridade das células, garantindo que suas funções essenciais sejam desempenhadas. Zhang et al. (2015) compararam concentrações distintas de 
zinco aplicadas à dieta e constataram que a atividade metabólica sofre interferência positiva em dose maiores de zinco, indicando que este elemento tem potencial protetor na sobrevivência destes insetos. A conclusão do estudo demonstra que a suplementação da dieta de abelhas melíferas com zinco, elemento presente na enzima Cobre/Zinco - Superóxido Dismutase (Cu/Zn - SOD), em doses acima de $30 \mathrm{mg} . \mathrm{kg}^{-1}{ }^{-1}$ satisfaz às necessidades nutricionais desta enzima para abelhas operárias, contribui no enriquecimento nutricional da geléia real que alimenta a rainha e melhora a saúde das larvas.

Contribuindo com os resultados dos achados sobre a interferência positiva da alimentação no metabolismo antioxidante, existem evidências de que o consumo de ácido ascórbico (vitamina C) diminui a prevalência e intensidade de infestação de parasitas em abelhas demonstrando que a redução nos indicadores de estresse oxidativo comprova o fortalecimento do sistema antioxidante e, por consequência, aumenta a sua capacidade de resistir a agentes agressores (FARJAN et al., 2014).

O ácido p-cumárico é onipresente na dieta natural das abelhas e pode funcionar como nutracêutico regulando os processos imunológicos e de desintoxicação. O pólen apresenta em sua composição, além do ácido citado, Pinocembrina e Éter 5-metílico de Pinobanksina que são indutores da expressão de genes de desintoxicação. Com essa indução, o metabolismo intestinal de coumaphos, acaricida usado em colmeias, é aumentado, apontando uma contribuição positiva no processamento orgânico deste composto químico e diminuição do impacto negativo dele na saúde das abelhas (MAO; SCHULER; BERENBAUM, 2013).

Vários estudos mostram que a qualidade nutricional da dieta é diretamente proporcional à capacidade da abelha de enfrentar desafios ou estressores. Buscando responder se a utilização de antioxidantes é capaz de mitigar tais problemas em abelhas, encontram-se diversas evidências que vinculam a melhoria na resposta ao estresse oxidativo do organismo desses insetos com a defesa contra estressores e patógenos como consequência correlata da suplementação da alimentação de abelhas com antioxidantes.

Os agrotóxicos se mostram capazes de inibir a proliferação de alguns patógenos nas abelhas, mas também afetam microorganismos benéficos à saúde dos animais e o sistema de controle de oxirredução, não validando essa consequência dita positiva do uso de agroquímicos nas abelhas. Por outro lado, o antioxidante contribui para melhoria em geral da sua saúde. Fica evidente que a natureza protetora de oxidação dos constituintes do pólen e outras fontes têm papel fundamental no atendimento às necessidades nutricionais e de resistência das abelhas.

Porém, é preciso que se desenvolvam mais estudos para determinar o nutracêutico que é mais adequado como antioxidante para as abelhas, visto que, dependendo da época, a floração é escassa, não fornecendo pólen suficiente para suprir a sua demanda por antioxidantes. Também é necessário identificar a fase do desenvolvimento em que é mais eficaz a suplementação da dieta e a dose ideal para garantir menor susceptibilidade aos agrotóxicos. Por fim, vale salientar que a suplementação da alimentação das abelhas é uma prática realizada comumente e, se melhor elaborada, oferece vários benefícios nutricionais e a saúde desses polinizadores. 


\section{Conflito de interesses}

Os autores declaram que a pesquisa foi conduzida na ausência de quaisquer potenciais conflitos de interesses.

\section{Declarações éticas}

Os autores confirmam que as diretrizes éticas adotadas pela revista foram seguidas por este trabalho, e todos os autores concordam com a submissão, conteúdo e transferência dos direitos de publicação do artigo para a Revista. Declaram ainda que o trabalho não foi publicado anteriormente nem está sendo considerado para publicação em outro em outro periódico.

Os autores assumem total responsabilidade pela originalidade do artigo, podendo incidir sobre os mesmos, eventuais encargos decorrentes de reivindicação, por parte de terceiros, em relação à autoria do artigo.

\section{Acesso aberto}

Este é um artigo de acesso aberto. A reprodução dos artigos da Revista em outros meios de comunicação eletrônicos de uso livre é permitida de acordo com a licença Creative Commons AtribuiçãoNãoComercial-CompartilhaIgual 4.0 Internacional (CC BY-NC-SA 4.0).

\section{ORCID}

Jéssica Scheid da Silva (iD https://orcid.org/0000-0002-5149-4034

Marcello Ávila Mascarenhas (D) https://orcid.org/0000-0001-6817-4718

\section{Referências}

ALAUX, C. et al. Interactions between Nosemamicrospores and a neonicotinoid weaken honeybees (Apis mellifera). Environmental Microbiology, v. 12, n. 3, p. 774-782, 2010. Wiley. DOI: http://dx.doi.org/10.1111/j.1462-2920.2009.02123.x.

ALAUX, C. et al. Nutrigenomics in honey bees: digital gene expression analysis of pollen's nutritive effects on healthy and varroa-parasitized bees. BMC Genomics, v. 12, 496 (2011). DOI: https://doi.org/10.1186/1471-2164-12-496.

AMARO, P.; GODINHO, J. Pesticidas e abelhas. Rev. de Ciências Agrárias, Lisboa , v. 35, n. 2, p. 53-62, jul. 2012. Disponível em http://www.scielo.mec.pt/scielo.php?script=sci_arttext\&pid=S0871018X2012000200005\&lng=pt\&nrm=iso. Acesso em: 24 mar. 2020. 
BARBOSA, D. B. et al. As abelhas e seu serviço ecossistêmico de polinização. Revista Eletrônica Científica da Uergs, v. 3, n. 4, p. 694-703, 30 dez. 2017. DOI: https://doi.org/10.21674/2448-0479.34.694-703.

BARKER, R. J.; LEHNER, Y. Laboratory comparison of high fructose corn syrup, grape syrup, honey, and sucrose syrup as maintenance food for caged honey bees. Apidologie, v. 9, n. 2, p. 111-116, 1978. Springer Science and Business Media LLC. DOI: https://doi.org/10.1051/apido:19780203.

BARROS, D. C. B. de. et al. Função da glândula mandibular na nutrição de abelhas Apis mellifera L. In: JORNADA CIENTÍFICA E TECNOLÓGICA DA FATEC, 6., 2017, Botucatu. Anais. Botucatu: 2017. p.1-2.

BATISTA, M. D. C. da S. et al. ALIMENTAÇÃO DAS ABELHAS: revisão sobre a flora apícola e necessidades nutricionais. Journal of Biology \& Pharmacy And Agricultural Management, v. 14, n. 1, p. 62-72, 2018. Disponível em: http://revista.uepb.edu.br/index.php/biofarm/article/view/4001/2444. Acesso em 06 abr. 2020.

BOILY, M.; ARAS, P.; JUMARIE, C. Foraging in maize field areas: a risky business? Science of The Total Environment, v. 601-602, p. 1522-1532, 2017. DOI: https://doi.org/10.1016/j.scitotenv.2017.06.014.

BRASIL, Empresa Brasileira de Pesquisa Agropecuária - Embrapa. TRAJETÓRIA DA AGRICULTURA BRASILEIRA. 2018. Disponível em: https://www.embrapa.br/visao/trajetoria-da-agricultura-brasileira. Acesso em: 18 abr. 2020.

BRASIL, Ministério da Saúde. Secretaria de Ciência, Tecnologia e Insumos Estratégicos. Departamento de Ciência e Tecnologia. Diretrizes metodológicas: elaboração de revisão sistemática e metanálise de ensaios clínicos randomizados - Ministério da Saúde - Secretaria de Ciência, Tecnologia e Insumos Estratégicos, Departamento de Ciência e Tecnologia. Brasília: Editora do Ministério da Saúde, 2012. 92 p.: il. - (Série A: Normas e Manuais Técnicos).

CLAUDIANOS, C. et al. A deficit of detoxification enzymes: pesticide sensitivity and environmental response in the honeybee. Insect Molecular Biology, v. 15, n. 5, p. 615-636, 2006. DOI: https://doi.org/10.1111/j.1365-2583.2006.00672.x. 
DE MATTOS, I. M.; SOARES, A. E. E.; TARPY, D. R. Mitigating effects of pollen during paraquat exposure on gene expression and pathogen prevalence in Apis mellifera L. Ecotoxicology, v. 27, n. 1, p. 3244, 2017. DOI: https://doi.org/10.1007/s10646-017-1868-2.

DESNEUX, N.; DECOURTYE, A.; DELPUECH, J. The Sublethal Effects of Pesticides on Beneficial Arthropods. Annual Review Of Entomology, v. 52, n. 1, p. 81-106, jan. 2007. Annual Reviews. DOI: http://dx.doi.org/10.1146/annurev.ento.52.110405.091440.

DÉMARES, F. J. et al. Sucrose Sensitivity of Honey Bees Is Differently Affected by Dietary Protein and a Neonicotinoid Pesticide. Plos One, v. 11, n. 6, p. 1-17, 2016. DOI: https://doi.org/10.1371/journal.pone.0156584.

DI PASQUALE, G. et al. Influence of Pollen Nutrition on Honey Bee Health: do pollen quality and diversity matter? Plos One, v. 8, n. 8, p. e72016-0, 2013. DOI: https://doi.org/10.1371/journal.pone.0072016.

DICKEL, F. et al. Increased survival of honeybees in the laboratory after simultaneous exposure to low doses of pesticides and bacteria. Plos One, San Diego, v. 13, n. 1, p. 1-18, 2018. DOI: https://doi.org/10.1371/journal.pone.0191256.

DOS SANTOS, C. F.; OTESBElGUE, A.; BLOCHTEIN, B. The dilemma of agricultural pollination in Brazil: beekeeping growth and insecticide use. Plos One, v. 13, n. 7, p. 1-13, 2018. DOI: https://doi.org/10.1371/journal.pone.0200286.

FAO, Organização das Nações Unidas Para Agricultura e Alimentação. FAO's Global Action on Pollination Services for Sustainable Agriculture. 20 mai. 2018. Disponível em: http://www.fao.org/pollination/en/. Acesso em: 23 abr. 2020.

FARJAN, M. et al. Supplementing with vitamin C the diet of honeybees (Apis mellifera carnica) parasitized with Varroa destructor: effects on antioxidative status. Parasitology, v. 141, n. 6, p. 770-776, 2014. DOI: https://doi.org/10.1017/S0031182013002126.

FERREIRA, I. C.F.R.; ABREU, R. M.V. Stress oxidativo, antioxidantes e fitoquímicos. Bioanálise, Ano IV , N. 2, p. 32-39, 2007. 
FOLEY, K. et al. Nutritional limitation and resistance to opportunistic Aspergillus parasites in honey bee larvae. Journal of Invertebrate Pathology, $\quad$ v. 111, n. $1, \quad$ p. $68-73,2012 . \quad$ DOI: https://doi.org/10.1016/j.jip.2012.06.006.

GAUTHIER, M. et al. Chronic exposure to imidacloprid or thiamethoxam neonicotinoid causes oxidative damages and alters carotenoid-retinoid levels in caged honey bees (Apis mellifera). Scientific Reports, v. 8, n. 1, p. 1-11, 2018. DOI: https://doi.org/10.1038/s41598-018-34625-y.

GONG, Y.; DIAO, Q. Current knowledge of detoxification mechanisms of xenobiotic in honey bees. Ecotoxicology, v. 26, n. 1, p. 1-12, 2016. Springer Science and Business Media LLC. DOI: https://doi.org/10.1007/s10646-016-1742-7.

GOULSON, D. et al. Bee declines driven by combined stress from parasites, pesticides, and lack of flowers. Science, v. 347, n. 6229, p. 1255957-1255957, 26 fev. 2015. American Association for the Advancement of Science (AAAS). DOI: http://dx.doi.org/10.1126/science.1255957.

GREGORC, A. et al. Effects of coumaphos and imidacloprid on honey bee (Hymenoptera: apidae) lifespan and antioxidant gene regulations in laboratory experiments. Scientific Reports, v. 8, n. 1, p. 1-13, 2018. DOI: https://doi.org/10.1038/s41598-018-33348-4.

HELMER, S. H. et al. Effects of realistic doses of atrazine, metolachlor, and glyphosate on lipid peroxidation and diet-derived antioxidants in caged honey bees (Apis mellifera). Environmental Science And Pollution Research, v. 22, n. 11, p. 8010-8021, 2014. DOI: https://doi.org/10.1007/s11356-014-2879-7.

HENRY, M. et al. A Common Pesticide Decreases Foraging Success and Survival in Honey Bees. Science, v. 336, n. 6079, p. 348-350, 29 mar. 2012. American Association for the Advancement of Science (AAAS). DOI: http://dx.doi.org/10.1126/science.1215039.

HERBERT, L. T. et al. Effects of field-realistic doses of glyphosate on honeybee appetitive behaviour. Journal Of Experimental Biology, v. 217, n. 19, p. 3457-3464, 2014. DOI: http://dx.doi.org/10.1242/jeb.109520.

JACK, C. J. et al. Effects of pollen dilution on infection of Nosema ceranae in honey bees. Journal of Insect Physiology, v. 87, p. 12-19, 2016. DOI: https://doi.org/10.1016/j.jinsphys.2016.01.004. 
JOHNSON, R. M. et al. Ecologically Appropriate Xenobiotics Induce Cytochrome P450s in Apis mellifera. Plos One, v. 7, n. 2, p. e31051, 3 fev. 2012. Public Library of Science (PLoS). DOI: https://doi.org/10.1371/journal.pone.0031051.

JUMARIE, C.; BOILY, M.; ARAS, P. Mixtures of herbicides and metals affect the redox system of honey bees. Chemosphere, Montréal, v. 168, p. 163-170, fev. 2017. Elsevier BV. DOI: https://doi.org/10.1016/j.chemosphere.2016.10.056.

KLEIN, A. M. et al. Importance of pollinators in changing landscapes for world crops. Proceedings Of The Royal Society B: Biological Sciences, v. 274, n. 1608, p. 303-313, 27 out. 2006. The Royal Society. DOI: https://doi.org/10.1098/rspb.2006.3721.

KOJIĆ, D. et al. Effect of fullerenol nanoparticles on oxidative stress induced by paraquat in honey bees. Environmental Science And Pollution Research, v. 27, n. 6, p. 6603-6612, 24 dez. 2019. Springer Science and Business Media LLC. DOI: https://doi.org/10.1007/s11356-019-07385-z.

LIAO, L. H.; WU, W.; BERENBAUM, M. R. Impacts of Dietary Phytochemicals in the Presence and Absence of Pesticides on Longevity of Honey Bees (Apis mellifera). Insects, v. 8, n. 1, p. 1-13, 14 fev. 2017. MDPI AG. DOI: https://doi.org/10.3390/insects8010022.

MAO, W.; SCHULER, M. A.; BERENBAUM, M. R. Honey constituents up-regulate detoxification and immunity genes in the western honey bee Apis mellifera. Proceedings Of The National Academy Of Sciences, v. 110, n. 22, p. 8842-8846, 29 abr. 2013. Proceedings of the National Academy of Sciences. DOI: https://doi.org/10.1073/pnas.1303884110.

MEIRELLES R. N. et al. O furto como um fator limitante na criação de abelhas. Pesquisa Agropecuária Gaúcha, v. 26(1), 82-91, 16 abr. 2020. DOI: https://doi.org/10.36812/pag.202026182-91.

MITTON, G. A. et al. Impacts of dietary supplementation with p-coumaric acid and indole-3-acetic acid on survival and biochemical response of honey bees treated with tau-fluvalinate. Ecotoxicology And Environmental Safety, v. 189, p. 1-8, fev. 2020. Elsevier BV. DOI: https://doi.org/10.1016/j.ecoenv.2019.109917. 
MOGREN, C. L.; DANKA, R. G.; HEALY, K. Larval Pollen Stress Increases Adult Susceptibility to Clothianidin in Honey Bees. Insects, v.10, n.1, p.1-10, 08 jan. 2019. MDPI AG. DOI: https://doi.org/10.3390/insects10010021.

MOMMAERTS, V. et al. Risk assessment for side-effects of neonicotinoids against bumblebees with and without impairing foraging behavior. Ecotoxicology, v. 19, n. 1, p. 207215, 13 set. 2009. Springer Science and Business Media LLC. DOI: https://doi.org/10.1007/s10646-009-0406-2.

PINHO, M. P.; CALDAS, C. A.; ZALUSKI, R. Alimentação artificial para abelhas Apis mellifera africanizadas. In: MOSTRA CIENTÍFICA FAMEZ / UFMS, 2018, Campo Grande. Anais [...]. Campo Grande, 2018. p. 1-2. Disponível em: https://famez.ufms.br/files/2015/09/ALIMENTA\%C3\%87\%C3\%83OARTIFICIAL-PARA-ABELHAS-Apis-mellifera-AFRICANIZADAS.pdf. Acesso em: 20 maio 2020.

PIRES, C. S. S. et al. Enfraquecimento e perda de colônias de abelhas no Brasil: há casos de CCD? Pesquisa Agropecuária Brasileira, Brasília, v. 51, n. 5, p. 422-442, maio 2016. FapUNIFESP (SciELO). DOI: https://doi.org/10.1590/S0100-204X2016000500003.

PISA, L. et al. An update of the Worldwide Integrated Assessment (WIA) on systemic insecticides. Part 2: impacts on organisms and ecosystems. Environmental Science And Pollution Research: pmid:29124633, p. 1-49, 9 nov. 2017. Springer Science and Business Media LLC. DOI: http://dx.doi.org/10.1007/s11356-0170341-3.

PREZENSKÁ, M.; SOBEKOVÁ, A.; SABOVÁ, L. Antioxidant enzymes of honeybee larvae exposed to oxamyl. Folia Veterinaria, Košice, v. 63, n. 4, p. 9-14, 1 dez. 2019. Walter de Gruyter GmbH. DOI: http://dx.doi.org/10.2478/fv-2019-0032.

QI, S. et al. Flumethrin at honey-relevant levels induces physiological stresses to honey bee larvae (Apis mellifera L.) in vitro. Ecotoxicology And Environmental Safety, v. 190, p. 1-8, mar. 2020. Elsevier BV. DOI: https://doi.org/10.1016/j.ecoenv.2019.110101.

SEREIA, M. J. Suplementos protéicos para abelhas africanizadas submetidas à produção de geléia real. Maringa: UEM, 2009. 92 f. Tese (Doutorado) - Programa de Pós-Graduação em Zootecnia da Universidade Estadual de Maringá. Centro de Ciências, Universidade Estadual de Maringa - PR. 
SHI, T. et al. Metabolomic analysis of honey bee, Apis mellifera L. response to thiacloprid. Pesticide Biochemistry and Physiology, Hefei, v. 152, p. 17-23, nov. 2018. Elsevier BV. DOI: https://doi.org/10.1016/j.pestbp.2018.08.003.

SIES, H. Strategies of antioxidant defense. European Journal Of Biochemistry, Wiley, v. 215, n. 2, p. $213-$ 219, jul. 1993. DOI: https://doi.org/10.1111/j.1432-1033.1993.tb18025.x.

SIMONE-FINSTROM, M. et al. Propolis Counteracts Some Threats to Honey Bee Health. Insects, v.8, n.2, p.1-20, 29 abr.2017. MDPI AG. DOI: https://doi.org/10.3390/insects8020046.

ŠKERGET, M. et al. Phenols, proanthocyanidins, flavones and flavonols in some plant materials and their antioxidant activities. Food Chemistry, v. 89, n. 2, p. 191-198, fev. 2005. Elsevier BV. DOI: https://doi.org/10.1016/j.foodchem.2004.02.025.

THOMPSON, H. M. Behavioural Effects of Pesticides in Bees - Their Potential for Use in Risk Assessment. Ecotoxicology, v. 12, n. 1/4, p. 317-330, fev. 2003. Springer Science and Business Media LLC. DOI: http://dx.doi.org/10.1023/a:1022575315413.

VALKO, M. et al. Free radicals and antioxidants in normal physiological functions and human disease. The International Journal Of Biochemistry \& Cell Biology, v. 39, n. 1, p. 44-84, jan. 2007. Elsevier BV. DOI: https://doi.org/10.1016/j.biocel.2006.07.001.

VANDAME, R. et al. Alteration of the homing-flight in the honey bee Apis mellifera L. exposed to sublethal dose of deltamethrin. Environmental Toxicology and Chemistry, v. 14, n. 5, p. 855, maio 1995. Wiley. DOI: https://doi.org/10.1002/etc.5620140517.

WONG, M. J.; LIAO, L.; BERENBAUM, M. R. Biphasic concentration-dependent interaction between imidacloprid and dietary phytochemicals in honey bees (Apis mellifera). Plos One, v. 13, n. 11, p. 1-15, 1 nov. 2018. Public Library of Science (PLoS). DOI: https://doi.org/10.1371/journal.pone.0206625.

ZHANG, G. et al. Zinc nutrition increases the antioxidant defenses of honey bees. Entomologia Experimentalis Et Applicata, v. 156, n. 3, p. 201-210, 29 jul. 2015. Wiley. DOI: https://doi.org/10.1111/eea.12342. 